Article

\title{
Chewing up the Wood-Wide Web: Selective Grazing on Ectomycorrhizal Fungi by Collembola
}

\author{
Clarisse Kanters ${ }^{1}$, Ian C. Anderson ${ }^{2}$ and David Johnson ${ }^{1, *}$ \\ 1 Institute of Biological and Environmental Sciences, University of Aberdeen, Cruickshank Building, \\ St. Machar Drive, Aberdeen AB24 3UU, UK; E-Mail: clarisse.kanters@gmail.com \\ 2 Hawkesbury Institute for the Environment, University of Western Sydney, Penrith, NSW 1797, \\ Australia; E-Mail: i.anderson@uws.edu.au \\ * Author to whom correspondence should be addressed; E-Mail: d.johnson@abdn.ac.uk; \\ Tel.: +44-122-427-3857; Fax: +44-122-427-2703.
}

Academic Editors: Burenjargal Otgonsuren and Eric J. Jokela

Received: 6 March 2015 / Accepted: 21 July 2015 / Published: 28 July 2015

\begin{abstract}
The mycelia of some symbiotic ectomycorrhizal fungi form extensive networks - the so called "wood-wide web" - that have key roles in biogeochemical cycling. By interacting with myriad soil organisms such as collembola, the fungi directly affect the functioning of above- and below-ground multitrophic interactions in ecosystems. Here we tested whether the grazing activities of collembola affected the growth of ectomycorrhizal fungi in single or mixed species axenic cultures, and their impact on ectomycorrhizal diversity in litterbags in the field. We also used ${ }^{14} \mathrm{CO}_{2}$ pulse-labelling to test the effects of collembola on respiratory losses of recent plant assimilate from external mycelium of ectomycorrhizal fungi in symbiosis with Scots pine or birch. We found that the effects of collembola varied across species, and caused a significant reduction in the amount of ${ }^{14} \mathrm{CO}_{2}$ released from external mycorrhizal mycelium from three of the eight species combinations but increased it in one. Selective grazing also significantly affected the community structure of ectomycorrhizal fungi. Our findings demonstrate the importance of collembola in regulating ectomycorrhizal fungal diversity and activity and below-ground pathways of carbon flow.
\end{abstract}

Keywords: biodiversity; soil invertebrates; multitrophic interactions; carbon turnover; selective grazing; pulse-labelling; ${ }^{14} \mathrm{CO}_{2}$ 


\section{Introduction}

Tree roots in temperate and boreal forests are heavily colonised by symbiotic ectomycorrhizal (ECM) fungi [1], which can form dense mycelial networks throughout soil; the so-called "wood-wide web" [2]. The amount of ECM mycelium in forests is enormous with current estimates ranging from 1 to $600 \mathrm{~m} \mathrm{~g}^{-1}$ soil, or 289 to $8000 \mathrm{~m} \mathrm{~m}^{-1}$ root [3,4]. ECM fungi exhibit a range of attributes that make them crucial for regulating biogeochemical cycles and ecosystem functioning. It is estimated that ECM fungi receive between $5 \%$ and $20 \%$ of the total amount of carbon (C) fixed by the plants [1]. Large components of this are released back to the atmosphere as soil $\mathrm{CO}_{2}$ efflux [5] and enter the decomposition cycle as the mycelium dies [6,7]. Identifying the biological factors that regulate the diversity and activity of ECM fungi is therefore crucial for understanding forest ecosystem functioning and biogeochemical cycling.

One factor often over-looked is the activities of grazing invertebrates. The extent of ECM mycelium in the surface horizons means that it comes into contact with a myriad of other soil organisms, particularly invertebrate groups like fungivorous collembola, which can reach densities of $2.4 \times 10^{5} \mathrm{~m}^{-2}$ in coniferous forests [8]. Microcosm studies have shown that collembola can have both positive and negative effects on nutrient uptake and growth of ectomycorrhizal seedlings [9,10]. The only investigation of the interactions between collembola and $\mathrm{C}$ turnover by mycorrhizal fungi was in a grassland experiment where collembola reduced the flux of recently fixed plant assimilate through arbuscular mycelial networks [11]. Whether a similar situation exists in ECM dominated forests is unknown. Additionally, the resilience of ECM fungal networks to grazing may be dependent on the extent of mycelial development. Established networks may be more resilient to grazing than those that are establishing, due to the ability of fungi to allocate resources from other parts of their mycelia [12].

The extent to which the feeding behaviour of collembola is specialised may determine their influence on the structure and function of ECM communities and contribute to the diversity of findings noted above. In the laboratory, collembola have been reported to show feeding preferences [13-15] providing evidence that collembola have the potential to affect ECM functional diversity. It is now widely recognised that we need to gain a better understanding of how organisms at different trophic levels interact to affect key ecosystem processes like $C$ turnover [16] but this is missing in the case of collembola and ECM fungi. Here we redress this by testing the hypotheses that (i) collembola exhibit grazing preferences for different ECM fungi, with consequences for the performance of individual fungi when grown in mixtures and allocation of recent assimilate to them; (ii) established mycelium will be more resilient to grazing than establishing mycelium; and (iii) grazing preferences of collembola will lead to changes in ECM fungal community structure in the field. We test these by using a combination of pure culture grazing experiments, ${ }^{14} \mathrm{CO}_{2}$ pulse-labelling of seedlings in the laboratory, and molecular analysis of ECM fungal mycelium in decomposing litter in the field.

\section{Materials and Methods}

\subsection{Grazing Preferences of Collembola on ECM Fungi in Single-Species and Mixed Species Cultures}

The experiment was designed to test the effects of collembola on ECM fungal growth when the fungi were either in early (establishing) or late (established) phases of growth, and either grown in 
single species or four-species mixtures. The experiment used petri dishes (diameter $9 \mathrm{~cm}$, height $1 \mathrm{~cm}$ ) with a base layer of $1 / 10$ th modified Melin-Norkrans (MMN) media minus malt extract $(25 \mathrm{~mL})$. A cellophane disk approximately $8 \mathrm{~cm}$ in diameter was placed over the set agar. Fungal cultures (Hebeloma crustuliniforme, Laccaria bicolor, Suillus bovinus and Paxillus involutus) were added as agar disks (3 mm diameter) and incubated at $25{ }^{\circ} \mathrm{C}$. To test for effects of collembola (Protaphorura armata) on growth of established fungi, eight collembola were added to the petri dishes after the fungi had grown for two weeks. The collembola were extracted from a mixed stand of Scots pine (Pinus sylvestris L.) and birch (Betula pendula Roth). To test for effects on fungi in their early phase of growth, 8 collembola were added to dishes at the same time as the fungal plugs. This design resulted in 80 petri dishes in total ( $n=4$ per treatment), although one set of single species cultures (Paxillus involutus) in the established phase were lost.

Linear growth of the fungus was measured by recording the colony radius along two graduated orthogonal lines at regular intervals for 16 days after the animals were added to the plates, and the mean rate of growth during this period was calculated and used for analysis.

\subsection{Effect of Collembola on Efflux of ${ }^{14} \mathrm{CO}_{2}$ by ECM Fungi}

This experiment utilised seedlings of birch and Scots pine grown in symbiosis with a range of ECM fungi (see below). The birch seedlings were surface sterilised by shaking with saturated calcium hypochlorite solution, rinsed in sterile water and germinated on water agar and transferred to a controlled environment cabinet. After the birch seeds had germinated (approx. 10 days), ectomycorrhizas were synthesised using the cellophane plate technique [17]. The Scots pine seedlings were treated in the same way except after germination, ECM synthesis was achieved in petri-dishes containing a 4:1 mix of sterile peat-vermiculite (PV) amended with modified (1/10th strength containing $1 \mathrm{~g} \mathrm{~L}^{-1}$ glucose, agar removed) Melin Norkrans solution. Each seedling was inoculated with one ECM fungal species (see below) by placing a plug of fungal hyphae directly onto the short roots formed by the Scots pine. Compartmentalised microcosms were constructed by gluing a self-made open plastic frame covered by a $50 \mu \mathrm{m}$ nylon mesh in the middle of standard $9 \mathrm{~cm}$ diameter petri dishes. A slot, closed afterwards with sterile lanolin, was made where the stem of the seedling protruded from the dish, giving the roots entrance to the space within the frame and the ECM mycelium access through the mesh into the side compartments. After fabrication, the microcosms were sterilised in a $17 \%$ ethanol bath and dried in a laminar flow cabinet. The dishes were filled half full with a 4:1 mix of sterile PV, and the pre-colonised seedlings were transferred into the central compartment. The pine seedlings were approximately 7 months old and the birch 2.5 months. The lid was fixed to the main dish and the custom made frames with Blu-tack ${ }^{\circledR}$ to provide a gas tight seal. Twenty-five (equivalent to $\sim 12,700$ per $\mathrm{m}^{-2}$ ) collembola ( $P$. armata), starved for one day, were added to one compartment of each dish during the transfer. The microcosms were transferred in propagators to a controlled environment chamber $\left(18 \mathrm{~h}\right.$ day, $\left.6 \mathrm{~h} \mathrm{night;} 18^{\circ} \mathrm{C}\right)$ and the development of mycelium into the side compartments visually monitored.

For birch, five different ECM species were used: Hebeloma crustuliniforme (Bull. ex St. Amans.) Quél., Paxillus involutus (Batsch. ex Fr.) Fr., Piloderma fallax (Lib.) Stalp., Piloderma byssinum (Karst.) Jül. and Amanita muscaria (L. ex Fr.) Lam. For pine, three fungal species were used: Paxillus 
involutus, Piloderma fallax and Suillus variegatus (Sw. ex Fr.) Kuntze. In total, 28 paired microcosms were prepared (three replicates of each combination except for Hebeloma crustuliniforme that had eight replicates and Paxillus involutus that had only two living replicates at the end of the experiment).

The ${ }^{14} \mathrm{CO}_{2}$ pulse labelling was undertaken ten days after the mycorrhizal seedlings were transferred and collembola were added (except for seven replicates of the Hebeloma crustuliniforme where labelling took place 34 days after transfer). The seedlings were exposed to ${ }^{14} \mathrm{CO}_{2}$ gas by placing the microcosms in a clear acrylic gas-tight chamber. Plants were labelled in two batches by placing $750 \mu \mathrm{L}$ of a $1500 \mu \mathrm{L}$ solution containing $500 \mu \mathrm{L}$ radioactive sodium carbonate $\left(\mathrm{NaH}^{14} \mathrm{CO}_{3} ; 37 \mathrm{MBq} \mathrm{L} \mathrm{L}^{-1}\right)$ and $1000 \mu \mathrm{L}$ of unlabelled $\mathrm{NaHCO}_{3}$ into the chamber and releasing the gas by addition of $20 \%$ lactic acid. The plants were exposed to the $\mathrm{CO}_{2}$ for $4 \mathrm{~h}$. Thereafter four pieces of parafilm were put on the PV in each microcosm on to which was placed filter papers $(3 \mathrm{~mm} \times 10 \mathrm{~mm})$ saturated with $150 \mu \mathrm{L} 2 \mathrm{M}$ sodium hydroxide $(\mathrm{NaOH})$. After the trapping period (3 days), the papers were removed, placed into 96 well plates and analysed by liquid scintillation counting.

\subsection{Effect of Collembola on ECM Community Structure of Mycelium Colonising Litter}

The experiment was undertaken at Culbin forest National Nature Reserve ( $57^{\circ} 38^{\prime} 8^{\prime \prime} \mathrm{N}, 3^{\circ} 42^{\prime} 07^{\prime \prime} \mathrm{W}$ ) in Morayshire, Scotland, in a 120 year-old stand of Scots pine. The understorey vegetation was dominated by mosses (Rhytidiadelphus triquetrus (Hedw.) Warnst., Pleurozium schreberi (Brid.) Mitt. and Hylocomium splendens (Hedw.) Schimp.) but also contained occasional higher plants (Goodyera repens (L.) R. Br., Calluna vulgaris (L.) Hull and Betula pendula Roth. seedlings). The soil profile consisted of a surface organic litter $(0-2 \mathrm{~cm})$, fermentation $(2-4 \mathrm{~cm})$ and humic $(4-12 \mathrm{~cm})$ horizons above deep aeolian sand deposits [18]. Twenty two litter bags were made from $50 \mu$ mylon mesh and contained $1.5 \mathrm{~g}$ fresh weight Scots pine needles that had been defaunated by freezing to $-80{ }^{\circ} \mathrm{C}$ for $48 \mathrm{~h} \mathrm{[11].} \mathrm{The} \mathrm{litter} \mathrm{was} \mathrm{collected} \mathrm{from} \mathrm{the} \mathrm{forest} \mathrm{floor} \mathrm{directly} \mathrm{underneath} \mathrm{trees} \mathrm{and} \mathrm{thus} \mathrm{was}$ non-sterile but still visibly intact. The 15 collembola ( $P$. armata) added to half the bags were from the litter and organic horizons of a Scots pine dominated stand and heat-extracted using Tullgren funnels. The litterbags were inserted in Bags were placed in pairs of the $\mathrm{F}$ horizon in October 2006 and were removed in August 2007 (mean winter surface soil temperature: $4^{\circ} \mathrm{C}$ ). \pm collembolan within $5 \mathrm{~cm}$ of each other. Each pair was $>3 \mathrm{~m}$ apart. At harvest, one pair of bags was lost, so the analysis was restricted to 20 bags. Half of the litter remaining in the bags was dried $\left(80^{\circ} \mathrm{C}\right)$ and the $\mathrm{C}$ and nitrogen (N) contents determined by elemental analysis (Na 1500 NCS, Fisons Instruments, Quorum Technologies Ltd, Lewes, UK), while the other half was used for analysis of ECM community composition using molecular methods.

DNA extraction and subsequent analysis using terminal restriction fragment length polymorphism (T-RFLP) followed established procedures developed at this site [19]. Briefly, genomic DNA was extracted [20] using FastPrep lysing matrix-E tubes (Qbiogene, Cambridge, UK) and a FastPrep bead beating system (Bio-101, Vista, CA, USA). The material was macerated for $2 \times 30 \mathrm{~s}$ at $5.5 \mathrm{~ms}^{-1}$. Fungal ITS regions were PCR amplified with FAM labelled ITS1F, and HEX labelled ITS4, primers [21,22] using previously described PCR conditions [23]. PCR products were subsequently digested with HinfI and $T a q \mathrm{I}$ restriction endonucleases and the resulting fragments were analysed on an ABI PRISM ${ }^{\mathrm{TM}}$ 3130xl genetic analyser (Applied Biosystems, Warrington, UK) with a GS-500 ROX internal 
size-standard. T-RFLP fragment sizes (in bp) were determined with GeneMapper V3.7 software (Applied Biosystems, Warrington, UK). All fragments $>50 \mathrm{bp}$, and with a peak height of $>50$ absorption units were exported and used for the identification of ECM species by comparing fungal community T-RFLP profiles generated from each litter sample to a database containing reference T-RFLP peaks for 118 known ECM fungi [23]. A species was considered present if all TRFs were detected within an error of $1.5 \mathrm{bp}$.

\subsection{Statistical Analysis}

Chemical data were analysed by Kruskall-Wallis test and ECM community composition by $\chi^{2}$ test, which compared the relative abundance of ECM fungal genera in litterbags with collembola (i.e., the expected distribution in nature) versus that seen in paired litterbags without collembola. Growth rates of fungi in pure culture were analysed by GLM in Minitab 16, and differences between means tested by Tukey Honestly Significantly Different tests. All data were checked for normality and equal variance. The release of ${ }^{14} \mathrm{CO}_{2}$ was analysed using a repeated measures procedure in SPSS to account for the paired nature of the collembola treatment nested within plant/ECM species treatment. Here the $\mathrm{ECM} /$ plant host combination was entered as a random factor in the GLM model and the data were $\log 10$ transformed. Differences between pairs were determined by least significant difference test.

\section{Results}

Collembola had significant negative effects on the growth of fungi in pure culture (Figure 1), but the strengths of the effects were dependent mainly on the species of fungi, but also whether they were in the establishing or established phase of growth. L. bicolor was consistently affected by grazing the most, and the growth rate of establishing mycelia decreased by $26 \times$ in single species culture in response to collembola. By contrast, collembola reduced the growth rate of the other three species of fungi by only $3 \times-8 \times$. These effects were amplified in the mixtures, where L. bicolor growth rate was $95 \times$ less in the presence of collembola compared to controls, while the growth rate of other species were only reduced between $2 \times$ to $4 \times$. In established mixtures of ECM fungi, L. bicolor was the only species where consumption led to negative radial extension.

In the pulse-labelling experiment, the capture of ${ }^{14} \mathrm{CO}_{2}$ varied considerably and this resulted in an overall significant effect of plant/ECM species combination $\left(F_{7,20}=18.3, p<0.001\right)$. However, this overall effect was driven almost entirely by Hebeloma crustuliniforme in symbiosis with birch (Hc-b). This combination released the most ${ }^{14} \mathrm{CO}_{2}$ (Figure 2) compared to other combinations regardless of whether collembola were present or absent, and the rate of ${ }^{14} \mathrm{C}$ release was almost double that of the other combinations. None of the other differences between species combinations were significant although in some cases they did vary substantially; for example the mean rate from Piloderma fallax/birch (Pf-b) was 7.1 Bq and in Paxillus involutus/birch (Pi-b) it was 5.3 Bq. Across all species combinations, collembola significantly $\left(F_{1,20}=6.7, p=0.018\right)$ reduced the rate of ${ }^{14} \mathrm{CO}_{2}$ release from external ECM mycelium. This amounted to an overall reduction of $14 \%$ from 8.9 to $7.6 \mathrm{~Bq}$. There was a trend for collembola to reduce ${ }^{14} \mathrm{CO}_{2}$ release in five of the eight combinations. However, there was a significant plant/ECM species $\times$ collembola interaction $\left(F_{7,20}=3.17 ; p=0.020\right)$, with collembola significantly reducing ${ }^{14} \mathrm{CO}_{2}$ release from 3 of the 8 plant/ECM species combinations 
(P. involutus/Scots pine, P. fallax/Scots pine and $P$. fallax/birch). In one combination (Suillus variegatus/Scots pine), collembola significantly increased ${ }^{14} \mathrm{CO}_{2}$ release.

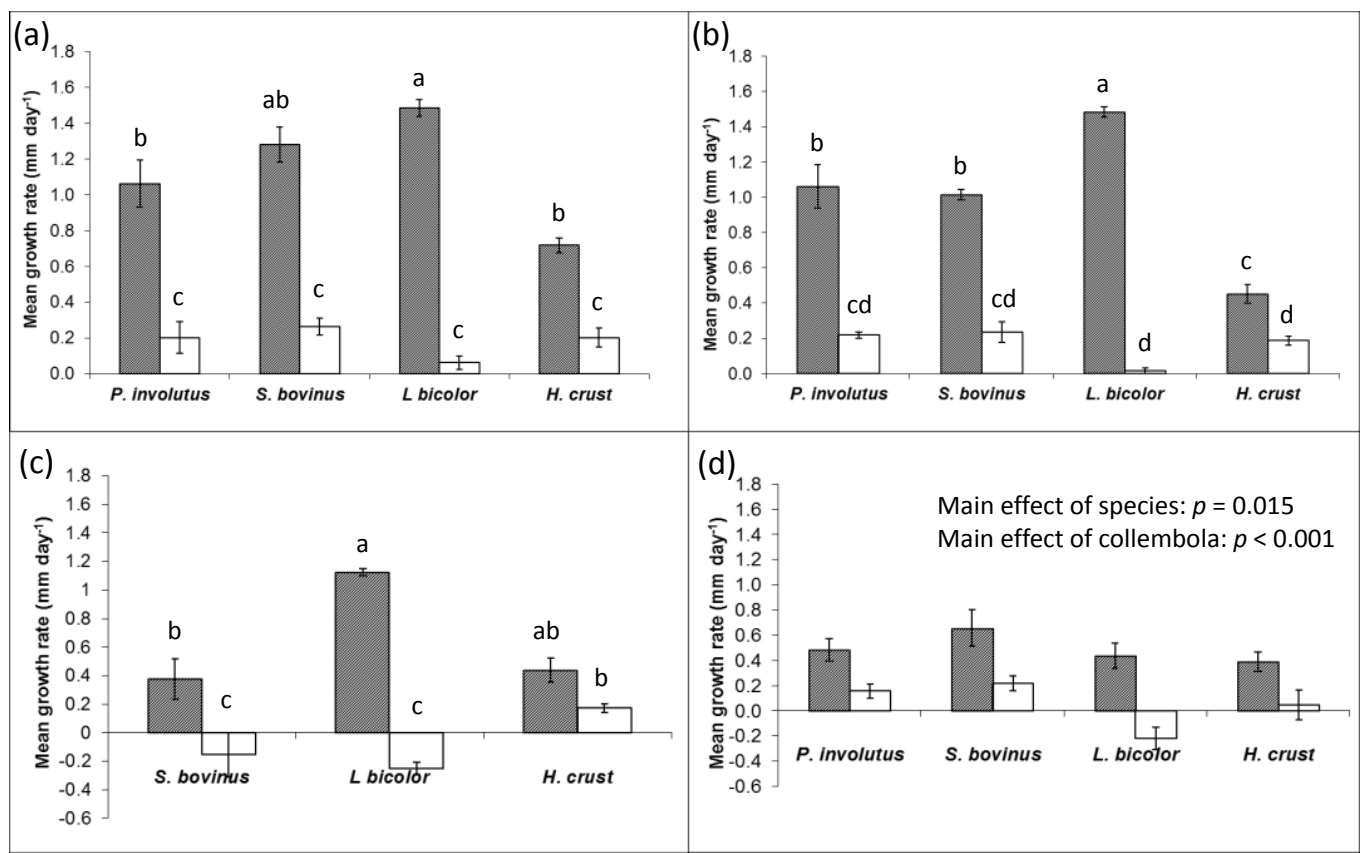

Figure 1. Radial extension of selected ECM fungi in pure culture in the absence (shaded) or presence (open) of collembola ( \pm SEM, $n=4)$. (a) Single species cultures and (b) mixed species cultures in the early, establishing phase of growth; and (c) single species cultures and (d) mixed species cultures in late, established phase of growth. Bars sharing a letter are not significantly different $(p>0.05)$.

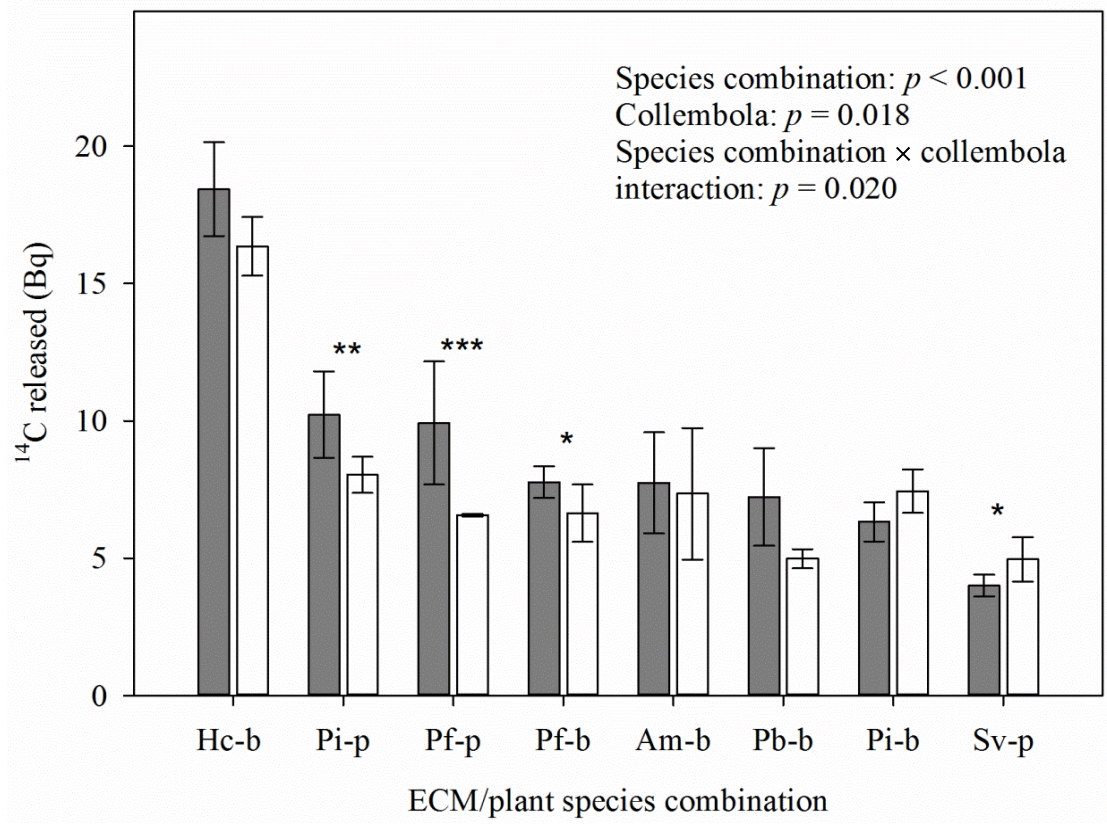

Figure 2. Mean efflux of ${ }^{14} \mathrm{CO}_{2}$ from external mycelium during a three day pulse-chase of different ECM fungi and plant combinations in the absence (shaded) or presence (open) of collembola (back transformed means \pm SEM). Species combinations: Hebeloma 
crustuliniforme $\times$ Betula pendula (Hc-b), Paxillus involutus $\times$ Pinus sylvestris $(\mathrm{Pi}-\mathrm{p})$, Piloderma fallax $\times$ P. sylvestris $(\mathrm{Pf}-\mathrm{p})$, P. fallax $\times$ B. pendula $(\mathrm{Pf}-\mathrm{b})$, Amanita muscaria $\times$ B. pendula $(\mathrm{Am}-\mathrm{b})$, Piloderma byssinum $\times$ B. pendula $(\mathrm{Pb}-\mathrm{b})$, , P. involutus $\times$ B. pendula $(\mathrm{Pi}-\mathrm{b})$, Suillus variegatus $\times$ P. sylvestris $(\mathrm{Sv}-\mathrm{p})$. Asterisk indicates significant difference between treatment pairs $(*=p<0.05 ; * *=p<0.01 ; * * *=p<0.001)$.

From the litterbags, a total of 20 ECM fungi were identified from DNA extracts of the pine needles (Figure 3). The effects of collembola were quite subtle, although the frequency distributions of the fungi differed between bags with and without collembola and there was a significant $(p<0.001$; $\chi^{2}$ statistic $=25.5 ; d f=7$ ) effect of collembola on ECM fungal community composition associated with the litter (Figure 3). Seven species were unique to bags without collembola, and four to bags with collembola. The species that responded negatively to collembola included Amanita fulva, Russula adusta, Amphinema byssoides, Lactarius pubescens, Bankera fuligineoalba and several Cortinarius sp. However, changes in the ECM communities were largely driven by negative effects of collembola on Cortinarius sp. and Amphinema byssoides, and positive effects on Phellodon tomentosus. The collembola led to considerable variation and a reduction in the $\mathrm{C}: \mathrm{N}$ ratio of the litter, which was $264: 1 \pm 105$ (mean \pm SE) in the bags with collembola compared to 83:1 \pm 18 in the controls $(p=0.033)$. There was no change in total $\mathrm{C}$ concentration, but a minor decrease in the $\mathrm{N}$ concentration of litter from $0.73 \% \pm 0.11 \%$ to $0.54 \% \pm 0.10 \%$ in the presence of collembola, but this difference was not significant.

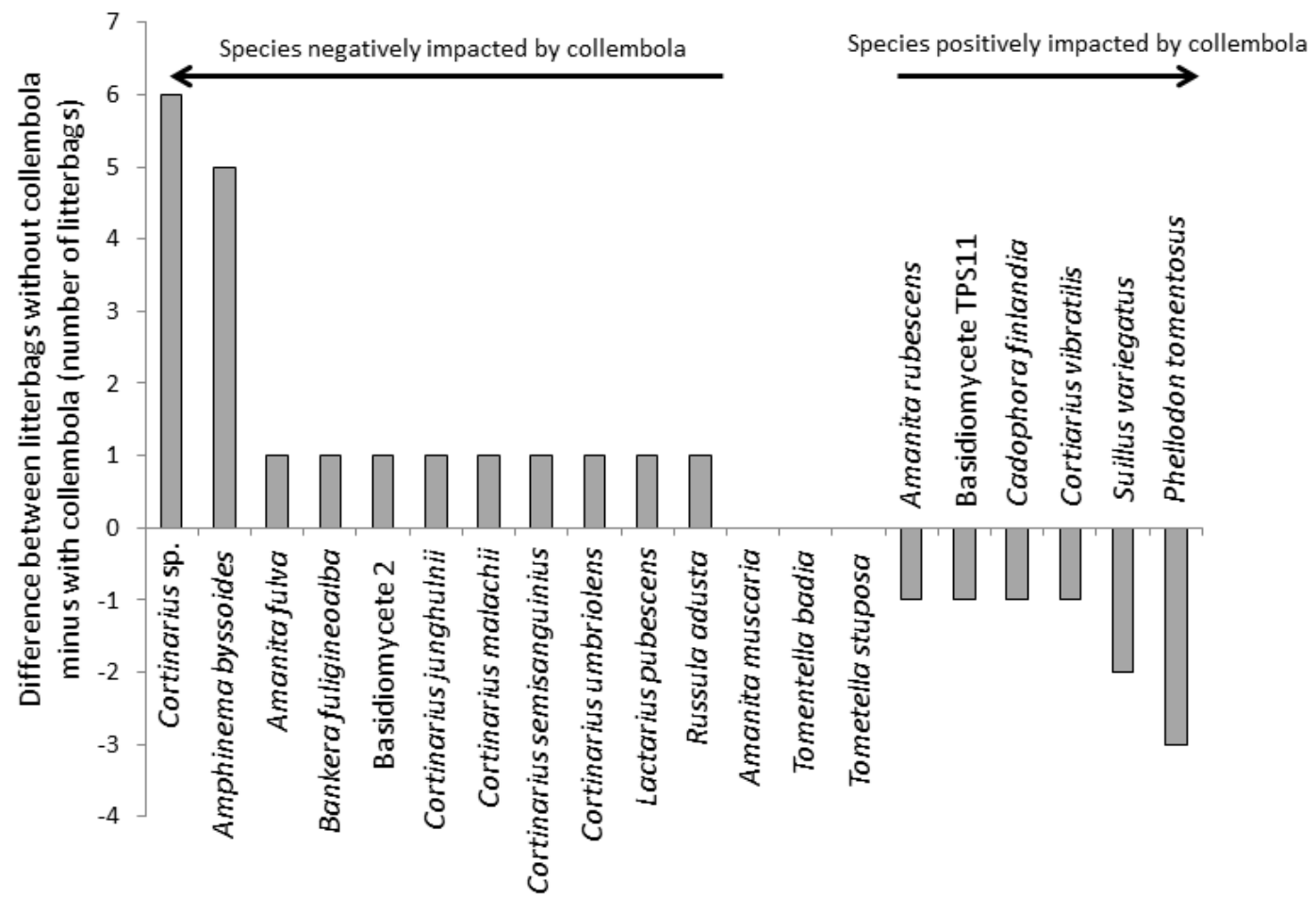

Figure 3. Response of ECM fungal community to collembola grazing in situ. The data show the difference in the number of litterbags without collembola minus the number of litterbags with collembola that contain a particular ECM fungal species. 


\section{Discussion}

We demonstrate that collembola can have direct effects on release of recent photosynthate from host plants via external ECM mycelium. These findings provide a mechanistic basis supporting indirect evidence suggesting that collembola obtain little C from above ground plant litter inputs [24], and that recent assimilate and ECM fungi can be important energy sources [25,26]. Past experimental designs have not been able to separate external mycelium from root systems but our experimental microcosms enable us to provide a direct connection between the presence of collembola and changes in flux of recently fixed ${ }^{14} \mathrm{CO}_{2}$.

The mycelium of ECM fungi has been shown to account for about $30 \%$ of soil $\mathrm{CO}_{2}$ efflux in coniferous forests [27], and is major source of $C$ for saprotrophic microorganisms [12,13]. Our results suggest that collembola may have a key role in regulating below ground fluxes of $\mathrm{CO}_{2}$ and ultimately the release of $\mathrm{C}$ in soil respiration. Previous experiments undertaken in grassland have shown similar negative responses of soil $\mathrm{CO}_{2}$ efflux through the grazing actions of collembola on arbuscular mycorrhizal networks [11] and collectively these findings provide clear evidence of the importance of interactions between collembola and ECM fungi in regulating energy flux to soils. Further experiments are required to gain a better understanding of the magnitude of the effects on $\mathrm{C}$ fluxes from ECM fungi under field conditions.

The data from the pulse-labelling experiment showed that the effects of collembola on release of ${ }^{14} \mathrm{CO}_{2}$ from external mycelium was dependent on the ECM species involved; for example, collembola were found to have negative (e.g., P. fallax with birch), positive (Suillus variegatus with Scots pine) and neutral (e.g., P. bysinnum with birch) effects. We do not know the mechanism behind these differences, but laboratory studies have suggested that collembola exhibit preference for nutritionally rich fungi that improve their fecundity [28] and increase the amount of senescing hyphae [29]. In our experiment, we also found differences in the feeding preferences of collembola in systems comprising single species and mixed species of ECM fungi. For example, L. bicolor was always strongly negatively affected by collembola, whereas $H$. crustuliniforme still managed to grow in the presence of collembola, albeit at a reduced rate than in the absence of collembola. Nevertheless, the experimental design prevented us from identifying if these effects were specific at the species, genus, or family level. We also found that grazing had similar effects on growth of both established and establishing mycelium for most ECM species. H. crustuliniforme was the only fungus where significant effects of collembola could not be found on the growth of established versus establishing mycelium. Thus, there was only very limited evidence to support our second hypothesis. The responses of ECM fungi to collembola grazing in the laboratory raises the possibility that under more natural situations collembola may have varying effects on host/fungus combinations. However, like several laboratory experiments testing feeding preferences of collembola, our work suffers from the collembola being forced to feed only on the fungi provided to them. Given choice, collembola may exhibit preferences for saprotrophic rather than mycorrhizal fungi, as seen in arbuscular mycorrhizal systems [30]. Nevertheless, in the F and $\mathrm{H}$ horizons Scots pine forests, the fungal community is usually dominated by ECM fungi [4]. In addition, our data using mixtures in pure culture clearly indicate a degree of preference within ECM fungi. 
We therefore undertook a field experiment to determine whether grazing preferences were seen under natural conditions and whether this affected nutrient release from litter. We found that collembola had a significant but relatively subtle impact on the community composition of ECM fungal mycelium that was colonising the litter. Most species identified were rare and only occurred in a small number of litterbags. The species that responded most negatively to collembola included Amphinema byssoides and a group of Cortinarius sp. This lends some support under ecologically relevant conditions for the findings of pure-culture laboratory experiments, including our own reported here, which suggest collembola can exhibit feeding preferences $[13,15]$.

\section{Conclusions}

Our findings show that there is selective grazing of ECM fungi in pure culture, and that this is reflected to a certain extent in the field and in the release of photosynthetically derived $\mathrm{C}$ from hyphal respiration. Because ECM fungal diversity is important in regulating a number of ecosystem properties such as seedling establishment, plant nutrition, water uptake, and soil respiration [1], soil invertebrates may have additional effects that warrant further investigation. Our study therefore supports ideas whereby interactions among different trophic groups below-ground can influence soil biodiversity and regulate ecosystem functioning [16].

\section{Acknowledgments}

This work was supported by the Natural Environment Research Council (NE/C507510/1). We thank S. Van der Linde, A. Sim, L. Shivraj, and P. Parkin.

\section{Author Contributions}

David Johnson designed the experiments, Ian C. Anderson led the molecular analysis, Clarisse Kanters did the field and laboratory work, David Johnson and Clarisse Kanters analysed the data, all authors wrote the paper.

\section{Conflicts of Interest}

The authors declare no conflict of interest.

\section{References}

1. Smith, S.E.; Read, D.J. Mycorrhizal Symbiosis, 3rd ed.; Academic Press: London, UK, 2008; p. 800.

2. Simard, S.W.; Perry, D.A.; Jones, M.D.; Myrold, D.D.; Durall, D.M.; Molina, R. Net transfer of carbon between ectomycorrhizal tree species in the field. Nature 1997, 388, 579-582.

3. Leake, J.R.; Johnson, D.; Donnelly, D.P.; Muckle, G.E.; Boddy, L.; Read, D.J. Networks of power and influence: The role of mycorrhizal mycelium in controlling plant communities and agroecosystem functioning. Can. J. Bot. 2004, 82, 1016-1045.

4. Ekblad, A.; Wallander, H.; Godbold, D.L.; Cruz, C.; Johnson, D.; Baldrian, P.; Björk, R.G.; Epron, D.; Kieliszewska-Rokicka, B.; Kjöller, R.; et al. The production and turnover of extramatrical mycelium of ectomycorrhizal fungi in forest soils: Role in carbon cycling. Plant Soil 2013, 366, 1-27. 
5. Högberg, P.; Nordgren, A.; Buchmann, N.; Taylor, A.F.S.; Ekblad, A.; Högberg, M.N.; Nyberg, G.; Ottosson-Lofvenius, M.; Read, D.J. Large-scale forest girdling shows that current photosynthesis drives soil respiration. Nature 2001, 411, 789-792.

6. Drigo, B.; Anderson, I.C.; Kannangara, G.S.K.; Cairney, J.W.G.; Johnson, D. Rapid incorporation of carbon from ectomycorrhizal necromass into soil fungal communities. Soil Biol. Biochem. 2012, 49, 4-10.

7. Wilkinson, A.; Alexander, I.J.; Johnson, D. Species richness of ectomycorrhizal hyphal necromass increases soil $\mathrm{CO}_{2}$ efflux under laboratory conditions. Soil Biol. Biochem. 2011, 43, 1350-1355.

8. Petersen, H.; Luxton, M. A comparative-analysis of soil fauna populations and their role in decomposition processes. Oikos 1982, 39, 287-388.

9. Setälä, H. Growth of birch and pine-seedlings in relation to grazing by soil fauna on ectomycorrhizal fungi. Ecology 1995, 76, 1844-1851.

10. Klironomos, J.N.; Hart, M.M. Food-web dynamics-Animal nitrogen swap for plant carbon. Nature 2001, 410, 651-652.

11. Johnson, D.; Krsek, M.; Wellington, E.M.H.; Stott, A.W.; Cole, L.; Bardgett, R.D.; Read, D.J.; Leake, J.R. Soil invertebrates disrupt carbon flow through fungal networks. Science 2005, 309, 1047.

12. Tlalka, M.; Bebber, D.P.; Darrah, P.R.; Watkinson, S.C.; Fricker, M.D. Emergence of self-organised oscillatory domains in fungal mycelia. Fungal Genet. Biol. 2007, 44, 1085-1095.

13. Shaw, P.J.A. A consistent hierarchy in the fungal feeding preferences of the collembola Onychiurus armatus. Pedobiologia 1988, 31, 179-187.

14. Schultz, P.A. Grazing preferences of 2 collembolan species, Folsomia candida and Proisotoma minuta, for ectomycorrhizal fungi. Pedobiologia 1991, 35, 313-325.

15. Hiol, H.F.; Dixon, R.K.; Curl, E.A. The feeding preference of mycophagous Collembola varies with the ectomycorrhizal symbiont. Mycorrhiza 1994, 5, 99-103.

16. Wardle, D.A.; Bardgett, R.D.; Klironomos, J.N.; Sëtala, H.; van der Putten, W.H.; Wall, D.H. Ecological linkages between aboveground and belowground biota. Science 2004, 304, 1629-1633.

17. Brun, A.; Chalot, M.; Finlay, R.D.; Söderström, B. Structure and function of the ectomycorrhizal association between Paxillus involutus (Batsch) Fr. and Betula pendula Roth. I. Dynamics of mycorrhiza formation. New Phytol. 1995, 129, 487-493.

18. Gauld, J.H. The soils of Culbin Forest, Morayshire: Their evolution and morphology, 587 with reference to their forestry potential. Appl. Geogr. 1981, 1, 199-212.

19. Genney, D.R.; Anderson, I.C.; Alexander, I.J. Fine-scale distribution of pine ectomycorrhizas and their extramatrical mycelium. New Phytol. 2006, 170, 381-390.

20. Griffiths, R.I.; Whiteley, A.S.; O’Donnell, A.G.; Bailey, M.J. Rapid method for coextraction of DNA and RNA from natural environments for analysis of ribosomal DNA- and rRNA-based microbial community composition. Appl. Environ. Microbiol. 2000, 66, 5488-5491.

21. Gardes, M.; Bruns, T.D. ITS primers with enhanced specificity for Basidiomycetes-Application to the identification of mycorrhizae and rusts. Mol. Ecol. 1993, 2, 113-118. 
22. White, T.J.; Bruns, T.D.; Lee, S.; Taylor, J. Amplification and direct sequencing of fungal ribosomal RNA genes for phylogenetics. In PCR Protocols: A Guide to Methods and Applications; Innis, M.A., Gelfand, D.N., Sninsky, J.J., White, T.J., Eds.; Academic Press: New York, NY, USA, 1990; pp. 315-322.

23. Pickles, B.J.; Genney, D.R.; Anderson, I.C.; Alexander, I.J. Spatial analysis of ectomycorrhizal fungi reveals that root tip communities are structured by competitive interactions. Mol. Ecol. 2012, 21, 5110-5123.

24. Pollierer, M.M.; Langel, R.; Korner, C.; Maraun, M.; Scheu, S. The underestimated importance of belowground carbon input for forest soil animal food webs. Ecol. Lett. 2007, 10, 729-736.

25. Högberg, M.N.; Biones, M.J.I.; Keel, S.G.; Metcalfe, D.B.; Campbell, C.; Midwood, A.J.; Thornton, B.; Hurry, V.; Linder, S.; Nashölm, T.; et al. Quantification of effects of season and nitrogen supply on tree below-ground carbon transfer to ectomycorrhizal fungi and other soil organisms in a boreal pine forest. New Phytol. 2010, 187, 485-493.

26. Malmström, A.; Tryggve, P. Responses of Collembola and Protura to tree girdling-Some support for ectomycorrhizal feeding. Soil Org. 2011, 83, 279-285.

27. Heinemeyer, A.; Hartley, I.P.; Evans, S.P.; de la Fuente, J.A.C.; Ineson, P. Forest soil $\mathrm{CO}_{2}$ flux: Uncovering the contribution and environmental responses of ectomycorrhizas. Global Chang. Biol. 2007, 13, 1786-1797.

28. Jorgensen, H.B.; Hedlund, K.; Axelsen, J.A. Life-history traits of soil collembolans in relation to food quality. Appl. Soil Ecol. 2008, 38, 146-151.

29. Kaneda, S.; Kaneko, N. The feeding preference of a collembolan (Folsomia candida Willem) on ectomycorrhiza (Pisolithus tinctorius (Pers.)) varies with mycelial growth condition and vitality. Appl. Soil Ecol. 2004, 27, 1-5.

30. Tiunov, A.V.; Scheu, S. Arbuscular mycorrhiza and Collembola interact in affecting community composition of saprotrophic microfungi. Oecologia 2005, 142, 636-642.

(C) 2015 by the authors; licensee MDPI, Basel, Switzerland. This article is an open access article distributed under the terms and conditions of the Creative Commons Attribution license (http://creativecommons.org/licenses/by/4.0/). 